\title{
A SURVEY OF PRIMARY PULMONARY TUBERCULOSIS IN WEST CORNWALL
}

\author{
BY \\ E. W. HUGHES AND R. L. RAY \\ From Tehidy Chest Hospital, Camborne, Cornwall
}

(RECEIVED FOR PUBLICATION DECEMBER 30, 1957)

The disappearance of waiting lists and the increasing number of empty beds in sanatoria bear witness to the success of modern methods in the treatment of pulmonary tuberculosis, and it is natural that these should now be directed towards prevention of the disease or, where infection has already occurred, towards arresting it while it is still in the early primary stage, that is, before it has had a chance to progress to the adult form.

In Great Britain there are two main schools of thought on the significance and danger of primary pulmonary tuberculosis, the conservative and the newer surgical school, and an extensive literature has grown up around the subject.

Macpherson (1954), from her long experience of tuberculous children, considers that many with primary lesions do not require treatment. Where there is only glandular enlargement of moderate degree supervision and regular radiographs are all that is usually required ; for gross enlargement a period of rest in bed is advised to minimize the risk of complications. The use of surgery in the treatment of collapsed lobes is discussed and the advantage of removing caseating disease is weighed against the risk of operation and the hardship to the child of a period away from home. Where the lesions are calcified satisfactory healing is implied and no treatment is needed. Bentley, Grzybowski, and Benjamin (1954), in their analysis of 1,049 children treated at High Wood, did not encounter any child with a segmental lesion, however ill, that succumbed to this illness, and they restrict the use of surgery to those cases developing severe post-tuberculous symptoms. Seal and Thomas (1956), on the other hand, are impressed by the frequency with which tubercle bacilli are found in the offending caseous lymph nodes and the incidence of caseation in the consolidated segments or lobes that they have removed in over 150 cases. In consequence, they feel that prophylactic adenectomy is sometimes indicated, together with resection of the affected portion of lung if the disease has already extended and is not responding to medical treatment. Huish (1956) also describes the application of surgical treatment to primary tuberculosis and lists his indications for operation. With the aid of more accurate pathological diagnosis he feels that there is a prospect of using surgery to prevent extension and damage in addition to resection where damage is irreparable.

The views of the two schools are summarized in Table I.

The main conflict of opinion hinges on whether the prognosis of hilar adenitis and segmental lesions is sufficiently doubtful to warrant surgical intervention. The answer to this question will only be forthcoming by following a representative number of children into adult life. To this end the isolated geographical situation of western

TABLE I

VIEWS OF CONSERVATIVE AND SURGICAL SCHOOLS COMPARED

\begin{tabular}{|c|c|c|}
\hline & Conservative School & Surgical School \\
\hline Prognosis & Good in the majority & Agreed that in general it is good \\
\hline $\begin{array}{l}\text { Extension } \\
\text { of disease } \\
\text { to lung } \\
\text { parenchyma }\end{array}$ & $\begin{array}{l}\text { Not of serious import. } \\
\text { Complications in- } \\
\text { frequent and res- } \\
\text { pond satisfactorily } \\
\text { to medical treatment }\end{array}$ & $\begin{array}{l}\text { Do not consider this to be in- } \\
\text { nocuous, histological study of } \\
\text { resected material having } \\
\text { shown a high incidence of } \\
\text { active caseating disease }\end{array}$ \\
\hline $\begin{array}{l}\text { Structural } \\
\text { damage to } \\
\text { broncho- } \\
\text { pulmonary } \\
\text { tissue }\end{array}$ & $\begin{array}{l}\text { Of little consequence } \\
\text { as it seldom causes } \\
\text { symptoms }\end{array}$ & $\begin{array}{l}\text { Invariably follows in the por- } \\
\text { tion of lung affected resulting } \\
\text { in bronchiectasis and loss of } \\
\text { function }\end{array}$ \\
\hline Treatment & $\begin{array}{l}\text { Rest and possibly } \\
\text { chemotherapy are } \\
\text { sufficient to treat all } \\
\text { but the minority }\end{array}$ & $\begin{array}{l}\text { For the majority medical means } \\
\text { are sufficient, but its limita } \\
\text { tions in preventing spread of } \\
\text { disease to lung and loss of } \\
\text { function must be recognized }\end{array}$ \\
\hline Surgery & $\begin{array}{l}\text { Required only if } \\
\text { asphyxia threatens } \\
\text { or there are trouble- } \\
\text { some symptoms; in } \\
\text { the case of bronchi- } \\
\text { ectasis these may } \\
\text { never develop, but, } \\
\text { should they do so } \\
\text { later, resection can } \\
\text { then be performed } \\
\text { with less risk }\end{array}$ & $\begin{array}{l}\text { Is indicated when glands en- } \\
\text { large and caseous contents } \\
\text { threaten to spread to bron- } \\
\text { chial tree. The aim of surgical } \\
\text { intervention being to: } \\
\text { (a) Save life where there is } \\
\text { tracheal obstruction } \\
\text { (b) Save function in those parts } \\
\text { of the lung not as yet } \\
\text { affected } \\
\text { (c) Prevent spread of disease to } \\
\text { the lung parenchyma }\end{array}$ \\
\hline
\end{tabular}


Cornwall with its chest clinics and hospital under the administration of one chest department suggested that a survey in this area might provide the opportunity to study the incidence and behaviour of primary disease relative to a specific population.

Western Cornwall is a peninsula separated from England by Bodmin Moor. It has a population of 266,389, mainly of Celtic stock. Although it is predominantly rural, and agriculture the main form of livelihood, it is known for its seaside resorts and for its china clay, tin mining, and granite industries. The latter two industries have dwindled in importance, but pneumoconiosis remains a problem, and its sufferers form an important reservoir of infection.

\section{Present-day Concept of Primary Pulmonary TUBERCULOSIS}

It is agreed that except for a small, indeterminate number of cases infection is caused by the human type bacillus and that the portal of entry is the respiratory passages. In the majority it is a symptomless benign process and the diagnosis is made in the few who have symptoms or are radiographed because of a history of contact. The earliest radiological abnormality is either the pulmonary focus or, more commonly, the enlarged hilar lymph nodes which together form the primary complex. In a minority the infection is not "contained" and it is almost universally accepted that extension occurs from the glands and not from the pulmonary focus. Strong supportive evidence is to be had from a study of the pathogenesis of tuberculous cervical adenitis. The primary is then situated in the tonsil, and though, when sectioned, tubercle bacilli are often found the tonsil rarely causes trouble, and it is to the glands that we have to look for evidence of disease. These may present as one or more firm, shotty glands, or at the other extreme as a mass of actively caseating glands discharging their contents through sinuses to the skin. Since these are superficially situated the complications to which they may give rise are few, for the overlying skin and fascia provide but a weak barrier to their enlargement and rupture. In the chest, however, the glands are intimately related to the bronchial tree, main blood vessels, pleura, pericardium, and oesophagus, and pressure upon, or erosion of, any one of these may cause complications (Table II).

We have used Bentley's system but have modified the disease groups to conform with the types we have met (Table III).
TABLE II

EFFECT OF ADENITIS ON TUBERCULOUS PROCESS

\begin{tabular}{|c|c|c|c|c|}
\hline & \multicolumn{2}{|c|}{ Mechanical } & \multirow{2}{*}{$\begin{array}{c}\text { Hyper- } \\
\text { sensitivity }\end{array}$} & \multirow{2}{*}{ Infective } \\
\hline & Partial & Complete & & \\
\hline $\begin{array}{l}\text { Trachea } \\
\text { Bronchi }\end{array}$ & $\begin{array}{l}\text { Stridor } \\
\text { Obstructive } \\
\text { emphys- } \\
\text { ema }\end{array}$ & $\begin{array}{l}\text { Asphyxia } \\
\text { Atelec- } \\
\text { tasis }\end{array}$ & $\begin{array}{l}\text { Epituber- } \\
\text { culosis }\end{array}$ & $\begin{array}{l}\text { Parenchymatous } \\
\text { disease: } \\
\text { Tuberculous con- } \\
\text { solidation } \\
\text { Tension cavity } \\
\text { Infiltrative disease }\end{array}$ \\
\hline $\begin{array}{l}\text { Pleura } \\
\text { Oesopha- } \\
\text { gus } \\
\text { Percar- } \\
\text { dium } \\
\text { Blood } \\
\text { vessels }\end{array}$ & \multicolumn{2}{|c|}{$\begin{array}{l}\text { Diverticulum mid- } \\
\text { third }\end{array}$} & $\begin{array}{l}\begin{array}{l}\text { Pleural } \\
\text { effusion }\end{array} \\
\begin{array}{c}\text { Pericardial } \\
\text { effusion }\end{array}\end{array}$ & $\begin{array}{l}\text { Tuberculous } \\
\text { pleural effusion } \\
\text { Oesophago-bron- } \\
\text { chial fistula } \\
\text { Tuberculous peri- } \\
\text { carditis } \\
\text { Miliary tuberculosis: } \\
\text { Tubercular menin- } \\
\text { gitis } \\
\text { Bone, renal tuber- } \\
\text { culosis, etc. }\end{array}$ \\
\hline
\end{tabular}

TABLE III

CLASSIFICATION AND TERMINOLOGY

\begin{tabular}{|c|c|c|}
\hline $\begin{array}{l}\text { Simple } \\
\text { primary } \\
\text { tuber-- } \\
\text { culosis }\end{array}$ & $\begin{array}{l}\text { Hilar }(+) \\
\text { adenitis } \\
\text { Hilar }(++) \\
\text { adenitis } \\
\text { Primary } \\
\text { complex }\end{array}$ & $\begin{array}{l}\text { Hilar glands the only visible evidence of } \\
\text { disease and not more than } 1 \mathrm{~cm} \text {. in } \\
\text { diameter } \\
\text { As above but glands more than } 1 \mathrm{~cm} \text {. in } \\
\text { diameter } \\
\text { Cases in which the pulmonary focus is } \\
\text { present with or without hilar glandular } \\
\text { enlargement }\end{array}$ \\
\hline $\begin{array}{l}\text { Pleural } \\
\text { effusion } \\
\text { group }\end{array}$ & $\begin{array}{l}\text { Simple pleural } \\
\text { effusion } \\
\text { Pleural effusion } \\
\text { and hilar } \\
\text { adenitis } \\
\text { Pleural effusion } \\
\text { and parenchy- } \\
\text { matous disease }\end{array}$ & $\begin{array}{l}\text { Cases in which effusion was only } \\
\text { evidence of disease } \\
\text { Cases with evidence of hilar glandular } \\
\text { enlargement as well as of fluid } \\
\text { Cases which had fluid and/or glandular } \\
\text { enlargement and parenchymatous dis- } \\
\text { ease }\end{array}$ \\
\hline \multicolumn{2}{|c|}{$\begin{array}{l}\text { Parenchymatous } \\
\text { disease }\end{array}$} & $\begin{array}{l}\text { This term embraces every case with pul- } \\
\text { monary opacities (other than those } \\
\text { caused by the pulmonary focus, } \\
\text { "epituberculosis ") which appeared at } \\
\text { the time of the primary infection or } \\
\text { were associated with hilar glandular } \\
\text { enlargement. These generally involved } \\
\text { bronchopulmonary units and were of } \\
\text { the consolidation collapse type. The } \\
\text { remainder, termed " infiltrates," opaci- } \\
\text { ties often of irregular outline, of patchy } \\
\text { distribution, and never segmental }\end{array}$ \\
\hline \multicolumn{2}{|c|}{$\begin{array}{l}\text { Miliary } \\
\text { tuberculosis }\end{array}$} & $\begin{array}{l}\text { Cases in which the typical miliary } \\
\text { shadowing was the only evidence of } \\
\text { lung disease }\end{array}$ \\
\hline
\end{tabular}

TABLE IV

PATTERN OF DISEASE ON PRESENTATION

\begin{tabular}{|c|c|c|c|c|c|c|c|c|}
\hline \multirow{2}{*}{ Disease Group } & \multirow{2}{*}{ No. } & \multirow{2}{*}{$\begin{array}{c}\text { Aver- } \\
\text { age } \\
\text { Age }\end{array}$} & \multicolumn{2}{|c|}{ Sex } & \multirow{2}{*}{$\begin{array}{l}\text { Contact } \\
\text { History }\end{array}$} & \multicolumn{3}{|c|}{ Side } \\
\hline & & & $\mathbf{M}$ & $\mathbf{F}$ & & $\mathbf{R}$ & $\mathbf{L}$ & $\overline{\mathbf{B}}$ \\
\hline $\begin{array}{l}\text { Simple primary } \\
\text { tuberculosis }\end{array}$ & 35 & 9 & 15 & 20 & $22(63 \%)$ & 16 & 14 & 5 \\
\hline $\begin{array}{l}\text { Pleural effusion } \\
\text { group }\end{array}$ & 37 & 15 & 20 & 17 & $12(32 \%)$ & 19 & 17 & 1 \\
\hline $\begin{array}{l}\text { Parenchymatous } \\
\text { disease } . \\
\text { Miliary disease }\end{array}$ & $\begin{array}{r}26 \\
1\end{array}$ & $\begin{array}{l}7 \frac{1}{2} \\
4\end{array}$ & $\begin{array}{r}12 \\
1\end{array}$ & 14 & $19(73 \%)$ & 11 & 14 & $\begin{array}{l}1 \\
1\end{array}$ \\
\hline Total & 99 & 9 & 48 & 51 & $54(54 \%)$ & 46 & 45 & 8 \\
\hline
\end{tabular}


TABLE V

EXTENSION OF DISEASE

\begin{tabular}{|c|c|c|c|c|c|c|c|c|c|c|c|c|}
\hline & & & \multirow{2}{*}{ No. } & \multirow{2}{*}{ No. Relapsed } & \multirow{2}{*}{$\begin{array}{l}\text { Contact } \\
\text { History }\end{array}$} & \multirow{2}{*}{$\begin{array}{c}\text { Time } \\
\text { Interval } \\
\text { (mth.) }\end{array}$} & \multicolumn{2}{|c|}{ Sex } & \multicolumn{3}{|c|}{ Side } & \multirow{2}{*}{$\begin{array}{l}\text { Average } \\
\text { Age (yr.) }\end{array}$} \\
\hline & & & & & & & $\mathbf{M}$ & $\mathbf{F}$ & $\mathbf{R}$ & $\mathbf{L}$ & $\mathbf{B}$ & \\
\hline \multirow[t]{2}{*}{ 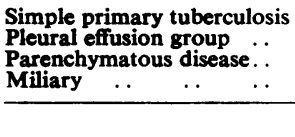 } & $\begin{array}{l}\cdots \\
\cdots \\
\cdots\end{array}$ & $\begin{array}{l}\cdots \\
\cdots \\
\cdots\end{array}$ & $\begin{array}{r}35 \\
37 \\
26 \\
1\end{array}$ & $\begin{array}{l}20(57 \%) \\
7(19 \%) \\
8(31 \%)\end{array}$ & $\begin{array}{r}13(65 \%) \\
1(14 \%) \\
6(75 \%)\end{array}$ & $\begin{array}{r}10 \\
9 \\
6\end{array}$ & $\begin{array}{l}8 \\
4 \\
2\end{array}$ & $\begin{array}{r}12 \\
3 \\
6\end{array}$ & $\begin{array}{r}11 \\
5 \\
5\end{array}$ & $\begin{array}{l}8 \\
1 \\
3\end{array}$ & $\begin{array}{l}1 \\
1 \\
-\end{array}$ & $\begin{array}{c}11 \\
14 \\
8 \frac{1}{2} \\
4\end{array}$ \\
\hline & Total & .. & 99 & $35(35 \%)$ & $20(57 \%)$ & & 14 & 21 & 21 & 12 & 2 & \\
\hline
\end{tabular}

Because our main interest lay in trying to establish why certain cases relapsed the various disease patterns and tables have been further subdivided into the "non-relapse" group, signifying no extension of disease since diagnosis, and the "relapse" group, signifying extension of disease since diagnosis.

\section{Case Material}

Included in this series are all those patients who were diagnosed as having primary pulmonary tuberculosis during the three-year period January, 1954, to December, 1956, or were still undergoing treatment for past primary disease; there were 99 patients of whom 24 were already under treatment when the survey began.

For clarity, the various types of disease have been grouped together (Table IV). The numbers in the three main groups are evenly distributed, and the proportion with parenchymatous disease is unusually high. This will be discussed later in the appropriate section. Details of average age, sex distribution, and side involved are also shown. Initially side and sex are involved in approximately equal proportions with the exception of the female predominance in the simple primary pulmonary tuberculosis group. The age, however, as has been noted by others, varied and was lowest in the parenchymatous disease group and highest in those with pleural effusions.

\section{Extension of Disease}

The disease spread in 35 of the 99 patients in only one of whom was it extrapulmonary (Tables V and VI). This was an infant of 11 months who presented with right hilar adenitis + and five months later developed consolidation/ collapse of the right middle and lower lobes, a right pleural effusion, miliary tuberculosis, and tuberculous meningitis. One other patient has developed skeletal tuberculosis, but is not included as the relapse occurred after the survey had closed.

Comparative figures in other series were very much lower. Seal and Thomas (1956), who followed up 298 cases of primary complex, found
TABLE VI

NATURE OF IMMEDIATE RELAPSE IN 35 CASES

\begin{tabular}{|c|c|c|c|c|}
\hline Lobar disease & .. & \multicolumn{2}{|c|}{ Single .. } & $\begin{array}{l}3 \\
2\end{array}$ \\
\hline Segmental disease & - & \multicolumn{2}{|c|}{$\begin{array}{l}\text { Multiple } \\
\text { Single .. }\end{array}$} & 2 \\
\hline Epituberculosis & . & $\cdots$ & $\cdots$ & 3 \\
\hline Obstructive emphysema & . & . & . & 2 \\
\hline Infiltrates $\cdots \quad \ldots$ & . & . & . & ${ }^{4}$ \\
\hline Paratracheal adenitis & . & . & . & 2 \\
\hline Dry pleurisy .. $\quad \ldots$ & $\cdots$ & . & . & 1 \\
\hline Pleural effusion & . & . & . & 7 \\
\hline \multirow{2}{*}{ Positive sputum only } & . & $\cdots$ & .. & $\mathbf{I}$ \\
\hline & & otal & . & 35 \\
\hline
\end{tabular}

that tuberculous complications developed in $16.4 \%$. From the same group Bentley and others (1954) record a figure of $15 \%$ and for the whole group $13 \%$. The incidence of extension in our primary complex group (simple primary tuberculosis) is high, $57 \%$, as was that of $35 \%$ for the whole series. The most significant features are the slight preponderance of females (most marked again in the simple primary pulmonary tuberculosis group) and the fact that right-sided disease was twice as likely to extend as that on the left.

There was evidence of parenchymatous involve- ? ment in 19. This also followed quickly in three other cases, the two with obstructive emphysema and one of the three with "epituberculosis." Thus the total number of patients in whom the disease extended to the lung was 22 , of whom four had positive sputum. Further complications $\frac{D}{0}$ arose as follows: one of the two patients with paratracheal adenitis required operation for $\mathcal{N}$ progressive enlargement causing tracheal compression; the one with dry pleurisy became $N$ sputum positive and one of the seven patients $\omega$ with pleural effusions developed miliary tuberculosis within a fortnight, having originally $\stackrel{O}{C}$ presented as a simple hilar adenitis $(+)$.

A more detailed analysis of all the tuberculous complications, together with the disease groups from which they arose, is given in Table II of the $\frac{\vec{D}}{\mathbb{D}}$ Appendix. This shows the incidence of complica- $\frac{O}{\square}$ tions (including extensions of disease to the fung $\stackrel{\mathbb{Q}}{\square}$ parenchyma) to be highest in the simple hilar adenitis group, breakdown occurring in $16(64 \%)$ 
TABLE VII

RELATION OF ENLARGED HILAR GLANDS TO PROGNOSIS

\begin{tabular}{|c|c|c|c|c|c|}
\hline & Number & $\begin{array}{c}\text { Non-relapse } \\
\text { Group }\end{array}$ & $\begin{array}{l}\text { Relapse } \\
\text { Group }\end{array}$ \\
\hline \multicolumn{3}{|c|}{$\begin{array}{ll}\text { Total number of patients } & \ldots \\
\text { Total with enlarged glands } & \ldots \\
\text { No. of glands that resolved } & . \\
\text { Average time taken to resolve.. }\end{array}$} & $\begin{array}{l}99 \\
62 \\
46\end{array}$ & $\begin{array}{l}64 \\
34(53 \%) \\
28(64 \%) \\
10 \text { months }\end{array}$ & $\begin{array}{l}35 \\
28(80 \%) \\
18(82 \%) \\
8 \text { months }\end{array}$ \\
\hline \multirow{3}{*}{ Side } & Right & .. & 27 & 13 & $14(52 \%)$ \\
\hline & Left ... & $\ldots$ & 28 & 18 & $10(36 \%)$ \\
\hline & Bilateral & $\ldots$ & 7 & 3 & 4 \\
\hline
\end{tabular}

of 25 patients. Unfortunately, our numbers were small and comparable figures are difficult to obtain, but Bentley and others (1954) in the High Wood series found that only $15 \%$ of the cases in the same group relapsed.

We were so impressed by the dangers of enlarged glands (Table VII) and the incidence of disease extension in our series that an attempt was made to investigate every patient in as much detail as possible, i.e., by tomography, bronchoscopy, and bronchography, to see (1) if there were any factors which influenced prognosis, and (2) whether it would be possible from a study of gland behaviour to recognize in which cases extension was likely.

Enlarged glands were present in $62(62 \%)$ of the 99 cases and, taking the series as a whole, were equally divided between the two sides of the mediastinum. " Radiological resolution," i.e., disappearance of the hilar opacity, occurred during the three-year period of observation in $46(74 \%)$.

Significant differences between the non-relapse and relapse groups were noted in the following respects: (1) A higher proportion of the relapse group had lymphadenopathy $(80 \%$ as compared with $53 \%$ ) ; (2) resolution occurred in fewer of the relapse group (64\% to $82 \%)$; (3) right-sided lymphadenopathy was more prone to complication than left, $52 \%$ of the patients who had rightsided involvement progressed, as opposed to $36 \%$ of those with glands on the left. The time taken for glands to "resolve" showed no significant difference, though in the relapse group it was slightly shorter, namely eight' months compared with 10 months. The figure is somewhat misleading, as it only includes those which resolved, and the proportion failing to do so was appreciably higher in this group.

\section{Relation of BRonchoscopic Findings to Prognosis}

We have encountered three main types of endobronchial abnormality (Table VIII) : (1) Endobronchitis, inflammation of the mucosa without loss of continuity or reduction in the size of the bronchial lumen; (2) indentation, narrowing of the bronchial lumen by a localized bulge over which the mucosa may or may not be inflamed but is intact; and (3) bronchial perforation, erosion of the bronchial wall at the base of which may be granulation tissue, necrotic material, pus, or recognizable caseous lymphoid tissue.

TABLE VIII

ANALYSIS OF BRONCHOSCOPIC FINDINGS IN ALL CASES

\begin{tabular}{|c|c|c|c|c|}
\hline & & No. & $\begin{array}{c}\text { Non- } \\
\text { relapse } \\
\text { Group } \\
\text { (64 Cases) }\end{array}$ & $\begin{array}{c}\text { Relapse } \\
\text { Group } \\
\text { (35 Cases) }\end{array}$ \\
\hline $\begin{array}{l}\text { Total bronchoscoped } \\
\text { No abnormality seen } \\
\text { Cases showing endobronchitis } \\
\text { Cases showing indentation .. } \\
\text { Cases showing erosion }\end{array}$ & $\begin{array}{l}\ldots \\
\cdots \\
\cdots \\
\cdots\end{array}$ & $\begin{array}{r}56 \\
31 \\
10 \\
2 \\
13\end{array}$ & $\begin{array}{l}34 \\
22 \\
5 \\
1 \\
6\end{array}$ & $\begin{array}{l}22 \\
9 \\
5 \\
1 \\
7\end{array}$ \\
\hline \multicolumn{2}{|c|}{ Total endobronchial abnormalities } & 25 & $12(35 \%)$ & $13(59 \%)$ \\
\hline
\end{tabular}

Bronchoscopic examination was performed in $56(56 \%)$ patients and no abnormality was detected in 31 patients, of whom $71 \%$ were in the non-relapse group. Though the proportion showing endobronchial disease is higher in the relapse group (59\% as opposed to $35 \%)$, the absolute numbers are almost equal and little help would be obtainable from this examination $a b$ initio in assessing prognosis. A study of the findings in the simple primary tuberculosis group (Table I, Appendix) suggests that it may help in this group of patients, for whereas all six of the non-relapse group were normal, seven of the 12 examined in the relapse group had endobronchial disease (endobronchitis two, bronchial perforations five).

Bronchial Perforation.-This was observed on bronchoscopy in 13 patients, all of whom had radiological evidence of glandular enlargement. It was twice as common on the left as on the right, nine to four respectively; the sexes were equally affected; and the average age of the 13 cases was $7 \frac{1}{2}$ years, range 1 to 17 . It was associated with "epituberculosis" in one, obstructive emphysema in three, collapse/consolidation of segments or lobes in nine (including three with obstructive emphysema), and gross pleural thickening in two. Permanent damage in the form of persistent collapse or bronchiectasis followed in eight ; in the remaining five both the bronchial perforation and pulmonary condition resolved. No relation was observed between behaviour of the erosion and age, sex, or side involved. The time taken for bronchial healing could not be estimated accurately as repeat examinations were not done at intervals of less than two to three months, but in 
the three cases in which the date of the primary infection could be determined (all had erythema nodosum) healing occurred in eight, nine, and 10 months respectively. Our impression was that chemotherapy had no effect upon the rate of healing. In only one patient has hilar glandular calcification been seen.

ObSTRuctive EMPHYSEMa.-This was noted in four patients in each of whom it was left-sided. It appeared within the first month of the illness in the two youngest patients, aged 3 and 7, both boys who had marked toxaemia and cough; one had stridor. The fever responded quickly to streptomycin and the radiological appearances reverted to normal over the course of two and seven months respectively. The younger is left with lingular bronchiectasis and a susceptibility to chest colds; the older has no residual damage or symptoms. Emphysema developed later, after six and nine months respectively, in the two girls aged $10 \frac{1}{2}$ and 11 years. The first (Case 3) had stridor but no toxaemia, and resolution followed in six months leaving a consolidated bronchiectatic apico-lower segment. This girl has remained well and symptomless for two years. In the second girl the emphysema was confined to the left upper lobe and was unaccompanied by symptoms. Within four months she had a pneumonic illness and was found to have consolidation of two segments of the upper lobe and a positive sputum.

Calcification.-This was observed in $38(38 \%)$ patients. The glands alone were affected in 17 , the glands and lung in 17, and in four it was seen in the lung only. The presence or absence of calcification in the glands did not affect the prognosis, but the time taken for it to appear did, being noticeably shorter (average six months) in the non-relapse group against an average of 14 months in patients who relapsed.

\section{Medical Treatment}

The results are shown in Table IX.

Seventy-eight patients were treated with bed rest, of whom 42 also had antituberculous drugs. The combination used in all but a few was streptomycin sulphate and isonicotinic acid hydrazide, the dosage being according to weight. The minimum duration of treatment was 10 weeks, and the average period of bed rest six months. Twentyone patients were not treated, either because it was not considered necessary by the physician in charge, or because it was declined.

The small numbers allow only a limited assessment of the value of therapy.

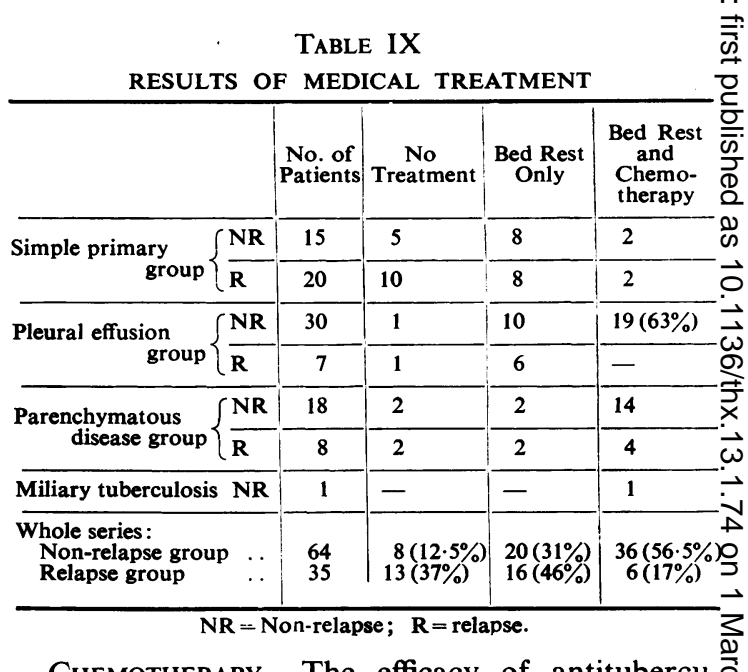

CHeMOTHERAPY.-The efficacy of antitubercu-⿳亠丷厂 lous drug treatment is most obvious in the pleural effusion group. None of the seven patients whoc relapsed had received treatment, as against $19^{\circ}$ $(63 \%)$ of the 30 patients who had no further trouble. It was also of symptomatic value when the primary infection was accompanied by fevero and constitutional upset, the symptoms invariablyő settling within the course of a week or two. $\varrho$ Whether it exerted any effect upon the course of primary tuberculosis is difficult to decide; but5 weight is lent to our impression that it has a beneficial influence by the following two findings:

(1) Of those patients whose disease extended in the simple primary tuberculosis and parenchym atous disease groups, only $21 \%$ had chemo therapy, against $50 \%$ of those in the non-relapse group.

(2) No haematogenous complications occurreof during the three-year observation period in any of the patients treated with chemotherapy, whereas in the follow-up of 241 children who had a primar complex Seal and Thomas (1956) reported $1 \%$ cases $(7 \%)$. In the two cases of miliary tuber 0 culosis the disease process extended early before chemotherapy had been given.

BED REST.-The value of bed rest in the treat ment of primary disease has always been difficult to assess, and, whereas in our series the direct evidence in its favour is unimpressive, the fact that the proportion of patients not so treated was very high in the relapse group suggests indirectl 5 that it is of benefit.

\section{CONTACT History}

A history of contact was recorded in 54 patient $(54 \%)$. It varied inversely with age, and the incio 
dence was highest in the parenchymatous disease group and lowest in the pleural effusion group. No correlation between contact history and the subsequent behaviour of the disease was observed.

\section{SYMPTOMS}

Seventy-two of the 99 patients presented with symptoms. These were classified as marked or mild and further subdivided into general and respiratory. In the majority, 61 , both general and respiratory tract symptoms occurred; in six the symptoms were constitutional only and in five they were confined to the respiratory tract with no general disturbance. The incidence was highest in the pleural effusion group of which only three had no symptoms and fell to approximately $50 \%$ in the remainder. Symptoms were marked in 10 where the average age was low (6 years), and of these eight had parenchymatous disease, one miliary tuberculosis, and one pleural effusion. It was not found that the presence or absence of symptoms where these were mild had any bearing on prognosis, but where they were marked and associated with parenchymatous disease in the younger age group the morbidity tended to be higher without influencing the final outcome.

\section{ERYTHEMA Nodosum}

This was the presenting feature in 10 patients, and was associated with a tendency to relapse, the disease extending later in eight.

\section{Parenchymatous Disease}

This was present in $31(31 \%)$ patients on diagnosis, of whom five also had pleural effusions and are classified as presenting in that group. The disease was of the infiltrative type in six and 25 (25\%) had segmental lesions.

AgE AND SEX.-There were 17 girls and 14 boys. The average age was $7 \frac{1}{2}$ years, range 14 months to 17 years in those with parenchymal disease only; when fluid was also present the average age was higher-14 years, range 14 months to 23 years.

SIDE.-Both lungs were almost equally involved, the right lung being affected in 14, the left lung in 16 , and in one the disease was bilateral.

The incidence of segmental lesions in our series is higher than that noted by other observers (Jones, Rafferty, and Willis, 1942, 12\% ; Richards, 1944, 14.4\% ; Roberts and Blair, 1950, 19\%; Thomas, Morgan, and Davies, 1954, 15\% ; Bentley and others, 1954, 19\% ; Derham, 1956, $22 \%)$. Our cases were not selected, and only those whose radiological opacities satisfied the present-day criteria of consolidation, collapse, or consolidation/collapse were regarded as having segmental lesions. One possible reason for the higher incidence is the frequent use which was made of antero-posterior and lateral tomography and bronchography; one or other of these investigations brought to light nine unsuspected segmental lesions which, on antero-posterior radiographs, would have been regarded as infiltrates or pleural opacities.

Parenchymatous Disease as a Complication. -Parenchymatous disease developed in a further 16 patients after diagnosis, of whom 14 had segmental lesions and two infiltrates (Appendix, Table II). The segmental complications occurred in seven $(44 \%)$ of the patients who presented with simple hilar adenitis $(+)$; in four $(44 \%)$ of those with hilar adenitis $(++)$; in two $(25 \%)$ of those with pleural effusion and hilar adenitis, and in one (4\%) who had a simple pleural effusion. The infiltrates followed in one case with a primary complex and in one with a simple pleural effusion. Extension of disease within the lung was observed in a further six patients, but since it occurred within the same bronchopulmonary unit it was regarded as evidence of continuing activity rather than of fresh disease; they were therefore not included. The time interval between diagnosis and the development of the parenchymal lesion varied between months and years. In the 13 patients in whom it was less than a year the average was five months, range two to 10 months ; in the remaining three, two of whom had pleural effusions, it ranged between two and three years.

FACTORS CONTRIBU IING To Relapse.-Factors possibly contributing to relapse in the 16 patients were sought by comparing details of age, sex distribution, side of disease, with those of their parent subgroups. The same preponderance of girls and right-sided disease was observed in both, 10 to six respectively. Likewise the average ages were similar except in the four extending from the hilar adenitis ++ subgroup in which it was appreciably lower, $5 \frac{1}{2}$ as opposed to 9 years. Too few were treated with chemotherapy to allow any conclusions on its value to be drawn, but it may be significant that only three of the 11 patients classified on diagnosis as hilar adenitis were treated with bed rest. The importance of enlarged glands and bronchial abnormalities in the pathogenesis of segmental lesions was confirmed; hilar adenitis was present in all but one, and endobronchial disease was noted in five of the nine patients bronchoscoped. 
Course of Parenchymatous Disease.-Our next concern was to study the course of the parenchymal disease, i.e., to determine in which patients there was a risk of further tuberculous complication and in which structural damage was likely to result. To get as complete a picture as possible, all who had parenchymal disease at any stage were grouped together to make a total of 47 patients. All but two were admitted to hospital for further treatment and investigation.

SIGNS AND SYMPTOMS.--In that symptoms bore little relation to the extent and behaviour of the underlying disease, they were not recorded in detail. Ten $(21 \%)$ had marked toxaemia and cough; $16(34 \%)$ had cough or general mild symptoms of short duration, and in $21(45 \%)$ the disease was "silent." Signs were of little help except in the case of stridor, obstructive emphysema, and pleural effusions, and significant abnormalities were noted in only 10 cases (32\%). In this group three patients had erythema nodosum and two phlyctenular conjunctivitis.

Site of Disease.-In the overall group the right lung was more frequently affected than the left, for which preponderance the inclusion of the 16 patients in whom disease appeared later was responsible. The upper lobes were more frequently affected than the right middle and lower lobes. Table $\mathrm{X}$ shows the distribution of lesions according to lobes and segments.

\section{TABLE X}

\section{ANATOMICAL DISTRIBUTION}

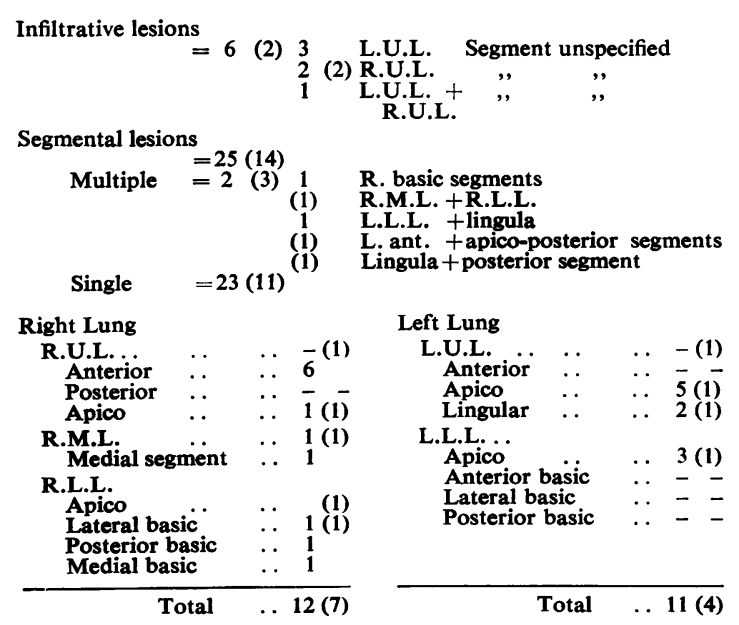

Figures in parentheses relate to 16 lesions occurring after diagnosis.
In assessing progress reliance was placed on $\stackrel{\overrightarrow{\bar{S}}}{\rightarrow}$ radiological rather than clinical findings, and five $\bar{c}$ patterns of behaviour were observed:

(1) Complete resolution

Where subsequent radiological examination, including tomography and bronchography, showed no evidence of residual disease or damage

(2) Apparent resolution

Where no residual abnormality was visible on "straight films but in which bronchographic changes known to be a legacy of tuberculous infection were found to persist

(3) Healing by calcification ...

Where the only evidence of residual disease consisted of discrete calcified mottling and no bronchial damage was found

(4) Partial resolution

Where only partial radiological improvement occurred

(5) No resolution

Where no radiological improvement occurred during the period of observation

Complete resolution occurred in 10 of the 47 을 patients, the lesions comprising collapse/consoli- $\overrightarrow{-}$ dation of lobes, two ; collapse/consolidation of segments, seven (upper lobes four, lower lobes $\stackrel{\widehat{S}}{\supset}$ three), and one infiltrate. Comparison with other $\vec{P}$ series is rendered difficult by the fact that similar $C$ criteria were not used and in only a small pro- $\infty$ portion was bronchography used. The terms "reaeration" and "re-expansion" are misleading and do not necessarily mean complete resolution, for in six of our patients a normal radiograph was accompanied by persistent bronchial damage. We $\stackrel{\square}{\stackrel{\perp}{\varrho}}$ submit that the figures for reaeration of seg- $\vec{B}$ mental lesions reported by Jones and others (1942) $\frac{3}{3}$ $50 \%$, Thomas and others (1954) $64 \%$, and Macpherson and Lutwyche (1950) 87\%, are high. Buto we cannot agree with Bentley that segmental lesions are only exceptionally followed by com-으 plete resolution, because resolution was complete $\underset{x}{\tilde{x}}$ in over a fifth of our cases.

Factors Influencing COURSE OF PARENCHYMATOUS DISEASE.-In this series no correlation was 0 observed between the side of disease, the nature of the lesion, i.e., whether there was consolida-음 tion/collapse of one or more segments or lobes $>$ or infiltrative disease, hilar adenitis, endobronchial abnormality, and the final outcome. The four N following factors appeared to have an influence o (Table XI) :

(1) Age.-Resolution was more likely to occur and to be complete in the older group. The average in the 10 whose lesions cleared com-co pletely was 10 years. Conversely the younger the $\mathbb{\Phi}$ child, the more likely was permanent damage to? follow.

(2) Duration of Glandular Enlargement.-

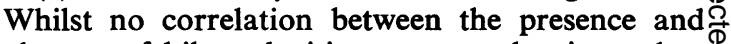
absence of hilar adenitis was seen, the time taken $\varnothing$ for the glands to resolve had a bearing on the issue, for in only one of the five patients in whom 
TABLE XI

FATE OF PARENCHYMAL LESIONS

\begin{tabular}{|c|c|c|c|c|c|c|c|c|c|c|c|c|c|c|c|c|c|c|}
\hline & & \multirow{2}{*}{$\begin{array}{l}\text { 岁 } \\
\text { ह } \\
\text { Z }\end{array}$} & \multirow[t]{2}{*}{ 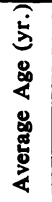 } & & ex & & Side & & \multirow[t]{2}{*}{ 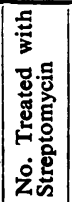 } & \multirow[t]{2}{*}{ 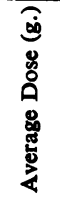 } & \multirow[t]{2}{*}{ 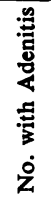 } & \multirow{2}{*}{ 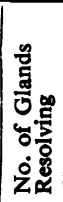 } & \multirow{2}{*}{ 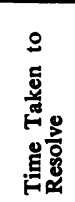 } & \multirow{2}{*}{ 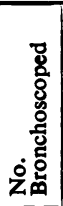 } & \multirow{2}{*}{$\begin{array}{l}\dot{\leftrightarrow} \\
\dot{\alpha} \\
\dot{z} \\
\dot{z}\end{array}$} & \multirow{2}{*}{ 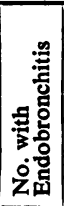 } & \multirow{2}{*}{ 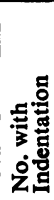 } & \multirow[t]{2}{*}{ 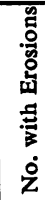 } \\
\hline & & & & $\mathbf{M}$ & $F$ & $\mathbf{R}$ & $\mathbf{L}$ & B & & & & & & & & & & \\
\hline 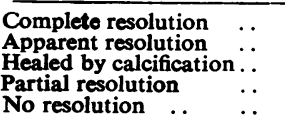 & $\begin{array}{l}. . \\
\because \\
.\end{array}$ & $\begin{array}{r}10 \\
6 \\
6 \\
16 \\
9\end{array}$ & $\begin{array}{l}10 \\
9 \\
7 \\
9 \\
6\end{array}$ & $\begin{array}{l}4 \\
2 \\
3 \\
6 \\
5\end{array}$ & \begin{tabular}{|r|}
6 \\
4 \\
3 \\
10 \\
4
\end{tabular} & $\begin{array}{l}6 \\
2 \\
2 \\
8 \\
5\end{array}$ & $\begin{array}{l}4 \\
4 \\
4 \\
7 \\
4\end{array}$ & $\begin{array}{l}\bar{z} \\
\overline{1}\end{array}$ & \begin{tabular}{|r|}
8 \\
6 \\
4 \\
15 \\
4
\end{tabular} & $\begin{array}{l}770 \\
36 \\
38 \\
77 \\
51\end{array}$ & $\begin{array}{r}8 \\
5 \\
33 \\
11 \\
8\end{array}$ & $\begin{array}{l}8 \\
5 \\
3 \\
5 \\
4\end{array}$ & $\begin{array}{r}8 / 12 \\
10 / 12 \\
5 / 12 \\
10 / 12 \\
21 / 12\end{array}$ & $\begin{array}{l}8 \\
4 \\
4 \\
9 \\
7\end{array}$ & $\begin{array}{l}2 \\
1 \\
4 \\
4 \\
-\end{array}$ & $\begin{array}{l}2 \\
2 \\
\frac{2}{3} \\
1\end{array}$ & $\begin{array}{l}\frac{1}{2} \\
\overline{2}\end{array}$ & $\begin{array}{l}3 \\
\frac{1}{2} \\
4\end{array}$ \\
\hline Total & .. & 47 & & 20 & \begin{tabular}{|l|}
27 \\
\end{tabular} & 23 & 23 & 1 & 37 & & 35 & 25 & & 32 & 11 & 8 & 3 & 10 \\
\hline
\end{tabular}

resolution was not seen did glandular regression occur, and then only after a year, whereas all the glands in the other groups resolved, and over a shorter period (average five to eight months), none taking longer than a year.

(3) Site of Disease.-Resolution was less likely to occur in middle and lower lobe disease than that of the upper lobes, seven of the 10 patients who had middle and lower lobe involvement ending with partial or no resolution as compared with only eight of the 21 who had upper lobe disease.

(4) Chemotherapy.-Thirty-seven (79\%) patients were treated with antituberculous drugs. In agreement with Wallgren (1956) we found that chemotherapy had little effect upon the immediate course of the parenchymal disease, but it may be significant that of the nine cases showing no evidence of resolution more than half did not receive chemotherapy whereas the proportion in the other behaviour groups was higher. Its value in reducing the incidence of haematogenous complications has already been mentioned.

The prognosis is worst in children under 5 when the associated glands take longer than a year to resolve and the disease is situated in the middle and lower lobes.

\section{BRONCHIECTASIS}

Bronchography was performed on 65 of the 99 patients and except in the older ones a general anaesthetic was used. In 34 abnormalities were found.

\footnotetext{
(1) Bronchiectasis Tubular or saccular dilatation of the bronchus and
its branches with or without stenosis of the bronchus at its origin (2) Bronchostenosis
Persistent constriction of the segmental or lobar
bronchus at its origin, the distal branches being normal

16 cases

2 ,

(3) Persistent non-filling

Repeated filling defect of a bronchopuimonary unit
}

(4) Indentation of the main bronchi.. $\quad \ldots \quad \ldots \quad \ldots \quad 3$ cases This filling defect was noted where there was bronchoscopic evidence of indentation or bronchial perforation and only those cases in which the remainder of the bronchial tree was normal are grouped under this heading

Table XII shows the localization of all parenchymatous disease lesions together with the distribution of the 31 bronchographic abnormalities.

Bronchial damage is in direct relation to the parenchymatous disease regardless of side or whether localized to the upper or middle and lower lobes. The percentage of abnormal bronchographic findings in those examined was: right lung $66 \%$, left lung $68 \%$, upper lobes $74 \%$, and middle and lower lobes $78 \%$.

Certain segments were more frequently affected than others (Table XIII).

AgE.-Whereas the average age in patients who had bronchiectasis, persistent filling defects, or no abnormality varied between 8 and 10 years, it was lower in the two cases with bronchostenosis only, namely, 3 and $2 \frac{1}{2}$ years respectively, and in the two cases in which this was present together with bronchiectasis, the ages were 3 years and 1 year.

Bronchiectatic Symptoms. - Two of our patients were left with persistent cough and sputum $(4.2 \%$ of the 47 patients who had parenchymatous disease). Both were infants aged 11 and 14 months respectively. The disease was basal and multilobar, in the right middle lobe in one and in the lingula and left lower lobe in the other, and the consolidation/collapse appeared to be permanent.

A further three patients, all of whom had damage to the right middle lobe, have had a susceptibility to chest colds since their illness and seem likely candidates for symptomatic bronchiectasis in later years.

The high incidence of bronchial damage accords with the experience of others who have carried out bronchography on cases of primary tuber- 
TABLE XII

LOCALIZATION OF DISEASE AND BRONCHIAL DAMAGE

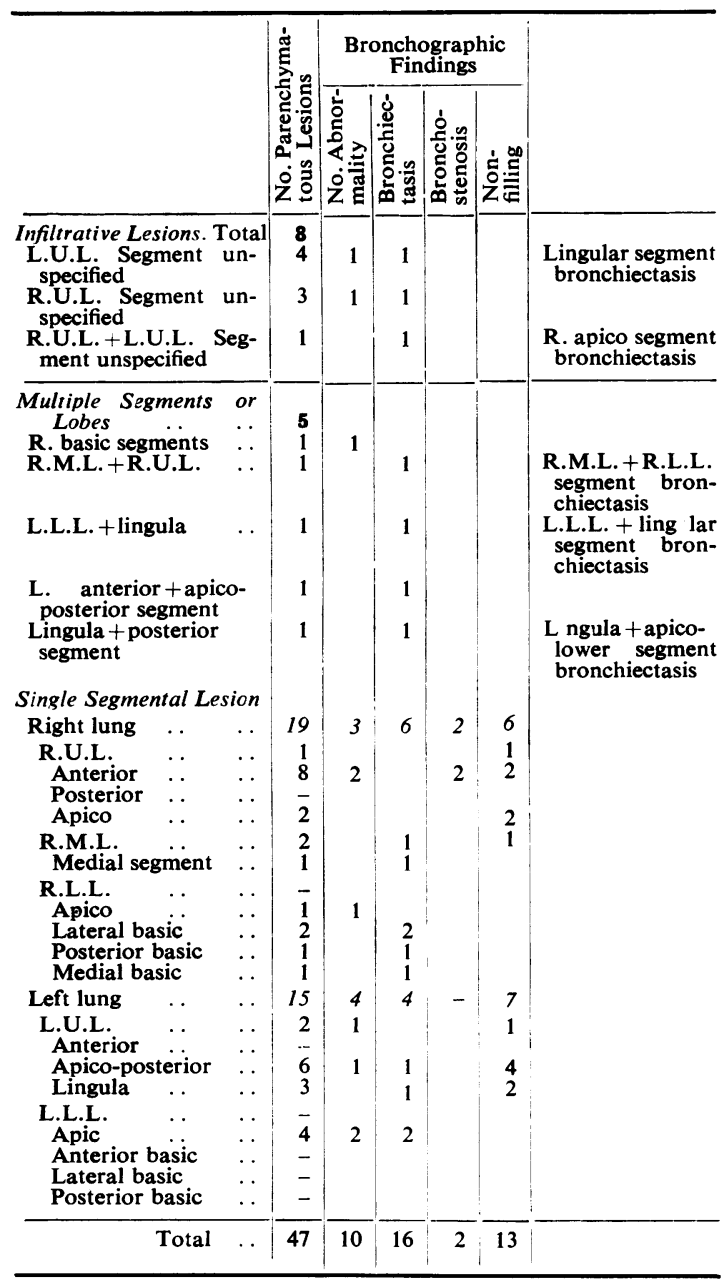

TABLE XIII

\begin{tabular}{|c|c|c|c|c|}
\hline & & $\begin{array}{l}\text { No. } \\
\text { Dis- } \\
\text { eased }\end{array}$ & $\begin{array}{c}\text { No. } \\
\text { Broncho- } \\
\text { grams }\end{array}$ & $\begin{array}{c}\text { No. } \\
\text { Bronchographic } \\
\begin{array}{c}\text { Abnormalities } \\
\text { Found }\end{array}\end{array}$ \\
\hline $\begin{array}{l}\text { L.U.L. } \\
\text { R.U.L. } \\
\text { R.M.L. }\end{array}$ & $\begin{array}{l}\text { Lingula segment } \\
\text { Apico-posterior segment } \\
\text { Anterior segment }\end{array}$ & $\begin{array}{l}6 \\
7 \\
8 \\
4\end{array}$ & $\begin{array}{l}6 \\
7 \\
8 \\
4\end{array}$ & $\begin{array}{l}6 \\
6 \\
4 \\
4\end{array}$ \\
\hline
\end{tabular}

culosis with segmental lesions. Jones, Peck, and Willis (1946) found it in $70 \%$ of a series of 34 patients, and Roberts and Blair (1950) in $92 \%$ of the 37 patients bronchographed out of 77 cases with segmental lesions. Bronchograms were done infrequently in the High Wood Hospital series.
Bentley and others (1954) differentiate between $\overrightarrow{\vec{s}}$ symptomatic and symptomless bronchiectasis and $\frac{7}{0}$ concentrated upon the former. Ten $(5.9 \%)$ of the $\frac{\bar{O}}{\mathrm{O}}$ 169 patients who had segmental lesions developed $\frac{}{\omega}$ symptoms of bronchiectasis of sufficient degree to $\overparen{\nabla}$ come to notice and in five of these symptoms did 응 not arise until after discharge from hospital. In क all 10 the lesions were in the middle or lower lobes $\overrightarrow{0}$ and lobectomy was performed in six ; no case of $\vec{\overrightarrow{ }}$ symptomatic bronchiectasis developed in any $\omega_{\sigma}$ upper lobe lesion. Derham (1956) does not $\vec{\overrightarrow{ }}$ record the number having bronchograms, but all $\vec{x}$ 10 of 75 patients with parenchymatous disease $\vec{\omega}$ submitted to surgery had bronchiectasis.

Morbidity is highest where multiple segments $\not$ are involved. Of the five patients in our series 을 four had bronchiectasis, in two of whom it was symptomatic, and three were sputum positive.

Parenchymatous disease of the middle and

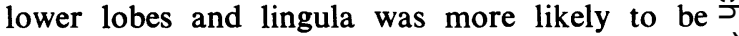
associated with bronchiectasis and showed less $\vec{\theta}$ tendency to heal than did disease in the upper 9 lobes. In six out of nine of the cases that did not 0 resolve at all there was bronchiectasis of the middle and lower lobes or lingula, and of the 16 cases showing partial resolution bronchiectasis was similarly distributed in 10 .

The bronchographic appearances returned to normal after six months in two cases classified on diagnosis as showing "non-filling": one had a consolidation of the left upper lobe and the other a collapse/consolidation of the right anterior segment.

Where the parenchymal lesion had healed with calcification (five cases) no bronchiectasis was $\times$ found in the four examined.

\section{Pleural Effusion}

We have classified all patients who had clinical 을 and radiological evidence of pleural fluid as pleural effusion. These were further subdivided into those with hilar gland enlargement and those with parenchymatous disease as defined in the 0 section on terminology.

The total number of patients having pleural $N$ effusion on diagnosis was $37(37 \%)$, of whom $24 \%$ had evidence of fluid only; in eight there was associated hilar glandular enlargement and five $\stackrel{0}{0}$

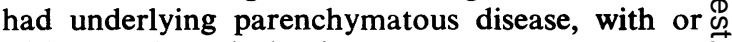
without enlarged glands.

AGE.-The average age of the whole group was 18 years; it was highest in the simple effusion $\stackrel{\mathbb{\Omega}}{\Omega}$ group (20 years), and appreciably lower where $\underset{\mathbb{Q}}{\mathbb{Q}}$ there was accompanying hilar adenitis or parenchymatous disease (14 years). 
SEX.-Both boys and girls were almost equally affected, except in the group of pleural effusion with hilar adenitis in which there was a preponderance of boys in the proportion of $6: 2$.

SiDE.-The two lungs were equally affected on diagnosis, both in the whole group and in the subgroups; in only one case was there bilateral effusion.

CONTACT History.-The history of contact was lowest in this group of cases and was obtained in only $12(32 \%)$ as against the figure of $54 \%$ for the whole primary series.

\section{EXTENSION OF Disease}

The disease extended in seven patients $(19 \%)$ during the three-year period of observation. Three, all of whom had right-sided effusions (one simple and two associated with glands), developed single segmental lesions; one an infiltrate in the left lung, when the original simple effusion was on the right; two developed further ipsilateral effusions, the fluid originally being simple in one and accompanied by glands in the other; and, finally, one developed enlarged paratracheal glands after presenting with a pleural effusion and parenchymal disease.

SIDE.-Extension occurred more frequently when the fluid was originally right-sided, extension following in five on the right against only one on the left, and one in which the fluid was bilateral.

CHEMOTHERAPY.-Though antibacterial therapy had little influence upon the behaviour of the effusion it was of value in preventing the development of further active tuberculosis; none of the seven patients who had extension of disease received chemotherapy against $62 \%$ of those who had no further complication. Emerson (1957), with a larger series, has reported similar results shown by a five-year morbidity rate in 83 patients with pleural effusion initially treated with adequate chemotherapy of only $4 \%$ against the usual figure of $30 \%$ in patients not so treated.

The place of chemotherapy in the treatment of tuberculous pleural effusions is unequivocally established.

Complication of Other Forms of Disease.Pleural effusion developed as a later complication in a further seven patients who presented with other forms of primary disease ; four had simple hilar adenitis, two were of the primary complex group, and one developed in a patient who presented with parenchymatous disease. In two of these cases miliary tuberculosis developed at the same time as the fluid.
The average age of this group was 15 years (range 1-20), females predominated (girls 5, boys 2 ), and both lungs were more or less equally involved (right four, left three). Enlarged glands were present in six (right three, left three). The interval between diagnosis and the appearance of fluid was six months (range 1-21 months). The effusion developed on the side affected on diagnosis in all seven cases.

Fate of 44 Cases of Pleural Effusions.Fluid was completely absorbed in every case ; the average time was three months (range two to 12 months). Apart from obliteration of the costophrenic angle resolution was complete and persisting residual pleural thickening was noted in only five, in which it was minimal and localized. During the course of the illness gross pleural thickening was present in another three patients in all of whom it was left-sided and was accompanied in two by bronchial perforation. Treatment with posture, rest, and chemotherapy resulted in complete resolution within a year. In the three patients with segmental lesions restitution was complete in one ; linear fibrosis probably referable to persistent sub-segmental collapse remains in one, and in the third (Case 4, W. J.) the lesion required resection. The infiltrative lesion, which was in fact a tuberculoma (Case 5, K. O.), was also resected. The paratracheal adenitis resolved completely, as it did in the remaining two patients who had further effusions.

Pathogenesis.-Although our investigations have shown hilar adenitis to be frequently associated with pleural effusions, the incidence was less than half $(43 \%)$, and it is clear that in this type of primary disease the glandular factor cannot always be invoked and that in the majority the infection reaches the pleura by some other means. In the two patients in whom there was associated miliary tuberculosis the spread must have been haematogenous and indirect. The absence of tuberculous complications in the patients treated with streptomycin suggests the same method of spread in the remainder.

In summary, it is seen that the pleural effusion was more likely to follow an unfavourable course in the younger age group when the fluid was rightsided, associated with hilar adenitis or segmental lesions, and chemotherapy had not been given.

\section{SURGICAL TreatMENT}

Eight cases were operated upon in the selection of which we were guided by the views expressed by Thomas (1952). 
Case 1.-F. M. was a girl aged 2 years, who presented initially with right hilar adenitis $(+)$ and collapse/consolidation of the basal segments of the right lower lobe. The glandular enlargement progressed over six months, despite bed rest, streptomycin (50 g.), and isoniazid, to a right paratracheal glandular abscess, producing tracheal compression. The resulting risk of respiratory obstruction was taken as an indication for operation. The glandular abscess was evacuated, giving immediate relief, and the child has since been completely symptom-free; the radiograph is normal; the segmental lesions resolved before the paratracheal abscess developed.

CASE 2.-D. P. P. was a girl of 14 months, who had marked right hilar enlargement and collapse/consolidation of the anterior segment of the right upper lobe. The segmental lesion was unaffected by five months in hospital treated with streptomycin, and this and the bronchoscopic findings, which showed the right main bronchus to be occluded by glands extending through the lateral wall, were taken as indications for thoracotomy. It was hoped that the lung changes might prove to be reversible after the removal of the obstructing glands. At operation the whole lobe was found to be solid and of liver-like consistency, with disease palpable throughout, and a right upper lobectomy, also removing the penetrating glands, proved necessary. Section showed the lobe to contain numerous caseating tubercles, little normal lung parenchyma remaining.

The immediate post-operative result was good, but some 12 months later the right hilar gland enlarged and perforated bronchi again. This has now subsided with further chemotherapy and rest. The child remains well.

CASE 3.-A. C. was a girl of $10 \frac{1}{2}$, who, presenting with marked hilar enlargement and an erosion, progressed over three months, despite treatment, to develop stridor, obstructive emphysema of the left lung, and collapse/consolidation of the apico-lower segment. Attempts to relieve the obstruction bronchoscopically were unsuccessful, and thoracotomy was undertaken ; but instead of the caseous glands encountered hitherto, the glands were firm, rubbery, and densely adherent to the pulmonary vessels and bronchi. In view of this, it was not considered practicable to remove either the glands or the affected segment, in which nodular masses could be felt. The chest was closed and with further chemotherapy the obstructive symptoms resolved in two months and the endobronchial changes resolved in six months. The child is left with a caseated bronchiectatic left apico-lower segment, but has remained well and symptomless for two years.

Case 4.-W. J., in the older age group, was a boy of 17 , who in 1951 developed bilateral pleural effusions. These cleared within three months, and subsequent progress was uneventful until a routine radiograph taken when he was "symptomless" showed a segmental homogeneous opacity in the right upper zone, which was associated with an eosinophilia of $37 \%$. The opacity cleared within a week. One $\overrightarrow{\vec{\omega}}$ month later a right pleural effusion developed. This again cleared rapidly, but while convalescing a positive sputum was obtained. Reappraisal of all his radiographs suggested that the enlarged right hilar gland, which had been present since diagnosis and not $\stackrel{\mathcal{D}}{\Omega}$ thought to be significant, was at fault and responsible for the two pleural effusions and a radiological opacity consistent with epituberculosis. This opinion was $\vec{\circ}$ strengthened when lateral tomography revealed an $\overrightarrow{\vec{H}}$ unsuspected collapse/consolidation of the lateral basic $\vec{w}$ segment, and confirmed at thoracotomy, when incision of the gland capsule disclosed liquefying caseous material. The contents were evacuated and the con- $\vec{\omega}$ solidated segment removed. Histological examination showed active progressive tuberculous disease. Progress thereafter was straightforward and he has kept well for three years.

CASE 5.-K. O., a boy of 17 , developed a tuberculoma in the apico-lower segment of the left lung 12 months after the uneventful and rapid resolution of a right pleural effusion with which he presented. Though this lesion contracted initially with treatment it extended again after five months and this was felt $\infty$ to justify its removal, the indications being as for adult disease. Histological sections of the specimen showed a caseating focus surrounded by tuberculous granulation tissue. This patient has remained well for over two years.

CASE 6.-J. C. was a girl of 5 in whom a left hilar adenitis, with an erosion and collapse/consolidation of $\overline{\bar{O}}$ the lingular segment, was found and in whom no improvement followed five months' hospital treatment with streptomycin. When, at bronchoscopy, granula- $\overline{0}$ tions were to be seen occluding the left upper lobe opening, we felt that thoracotomy was indicated for their removal. At operation the gland was aspirated (tubercle bacilli being present in the aspirate) and when it was found that the affected subsegment of the lingula could not be reaerated, this was removed. Histological section, however, showed fibrosis and chronic inflammatory infiltration. The child has remained well for two years.

CASE 7.-R.C. was a boy of $6 \frac{3}{4}$ presenting with a simple hilar adenitis (+). These glands, despite three months' bed rest, streptomycin, and isoniazid, enlarged $\mathrm{N}$ within six months leading to collapse/consolidation of $\Omega$ the lingula. The glands resolved but a segmental $N$ lesion persisted. Bronchography and tomography, $N$ which respectively showed non-filling and large $\omega$ nodular foci within the dense homogenous shadow, suggested that this was a consolidated, caseated, and functionless segment. In view of the risk of extension $\Phi$ and complete failure of chemotherapy, the segment $\stackrel{\mathscr{S}}{-}$ was removed. Histological sections of the specimen $T$ confirmed the presence of numerous actively caseous tubercles. This child has been well for nearly three years.

CASE 8.-Thoracotomy was carried out for progressive bronchial compression in M. G., a boy of 13 who 
had not responded to bed rest (12 months), streptomycin (50 g.), and isoniazid. This patient presented with marked bilateral hilar enlargement, bronchial perforation, and collapse/consolidation of the left apico-lower segment. Operation was aimed at removing the glands responsible, but in the event the glands could only be aspirated, removal being precluded by their close adherence to the pulmonary artery which also made impracticable resection of the associated segmental lesion.

All the patients tolerated thoracotomy well; there were no post-operative complications and all were cheerfully active within a week or two of operation.

Although there was no surgical morbidity, dissection of inflamed glands close to the pulmonary artery is not without danger, and some of our patients did give cause for concern during operation, particularly the very young. We reconsidered the eight surgical cases in the light of operation and histological evidence to see how many of the operations were necessary, how many of the patients may have derived benefit, and in how many the operation was of no value.

In two of our patients operation was essential. In Case 1 (F. M.) operation was necessary for the relief of incipient respiratory obstruction caused by a large paratracheal glandular abscess untreatable by any other means, and in Case 4 (W. J.) to obviate the risk of continued morbidity, it being unlikely that chemotherapy would have had any effect upon the chronically enlarged caseous node, already responsible for two pleural effusions, collapse/consolidation, and a positive sputum. In three patients, Case 2 (P. P. P.), Case 5 (K. O.), and Case 7 (R. C.), all of whom had caseous lung lesions with histological evidence of activity, it is possible that the risk of reactivation in later years has been materially reduced, for while it is agreed that many of these lesions regress and calcify, it is known that small foci of activity and viable bacilli may persist. Seal (1956), who has made a histological study of segments removed in patients with adult disease, has found frequent evidence of past infection. In two patients, Case 6 (K. C.) and Case 8 (M. G.), whose glands were evacuated, the duration of illness may have been shortened by operation, and in one, where the pus contained tubercle bacilli, the danger of spread prevented. In only one patient Case 3 (A. C.) was it not possible even to alleviate the obstructive symptoms.

We thought it would be of interest to review all the extensions to see in how many timely surgery might have prevented relapse. There were five such cases.
The first of these, Case 9 (E. O.), was a girl of 11 who presented initially with erythema nodosum and right hilar adenitis $(+)$. After a brief period of rest in hospital, the glandular enlargement resolved and she returned to school. She remained well for a year until overtaken by an acute respiratory illness, after which the sputum was found to be positive and radiographs showed consolidation/collapse of two segments of the left upper lobe. Looking back over the films it was realized that obstructive emphysema of the left lung had been developing for some three months before the appearance of the parenchymal disease. Treatment certainly, and thoracotomy if rapid resolution of the obstruction did not follow, might have enabled her to avoid the subsequent illness. Case 10 (P. J. B.) was a child of 7 years who, when seen as a contact, was found to have a left hilar adenitis $(+)$ for which it was felt that periodic clinic observation would be adequate. After four months a pulmonary opacity was noted in the left upper lobe and tomography of this, apparently very minor lesion, arranged. In the time taken for this examination the focus extended rapidly to produce cavitation in the left upper lobe together with a positive sputum. The third, Case 11 (J. B.), was a girl of 11 months who developed consolidation/collapse of the right middle and lower lobes, a right pleural effusion, miliary tuberculosis, and tuberculous meningitis, five months after the finding of a simple right hilar adenitis. In two further patients, both 3-year-old boys (Case 12 and Case 13), there was simple hilar adenitis $(+)$ associated with collapse/consolidation of the right middle lobe. Neither responded satisfactorily to rest and chemotherapy, and both are left with bronchiectasis and a susceptibility to chest colds with consequent loss of time from school.

These patients show that in the management of simple hilar adenitis, particularly in the young, medical supervision is not enough, and if despite bed rest and chemotherapy the glandular regression does not occur, or extension threatens, adenectomy should be considered.

\section{Discussion}

In our endeavour to show the incidence of primary pulmonary tuberculosis we were helped not only by the isolation of western Cornwall but also by the fact that in 1954, when our survey began, the scheme for the B.C.G. vaccination of 13-year-old schoolchildren had been extended to cover the whole area, which made available the total number of children who were aged 13 each 
year and the proportion who were Mantoux positive. Details are shown in the Appendix (Table III). The tuberculin-positive reactor rate is in the region of $20 \%$ and in line with the figures obtained in other rural areas. From the same age group during this period we had 13 children who had active primary disease, four of whom presented in the first year, eight in the second, and one in the third year, and thus the overall incidence of primary pulmonary tuberculosis in children aged 13 who were infected was approximately $1 \%$.

Though the incidence is low and there were no deaths, the fact that the disease progressed in over a half and that $10 \%$ became sputum positive shows that primary disease carries a significant morbidity and stresses the need of treatment to prevent the later development of adult phthisis and minimize the risk of structural damage with consequent functional loss. The Joint Tuberculosis Council in its report of 1955 on the "Changing Pattern of Tuberculosis" considered that primary disease is likely to play an even more important role in the causation of adult disease, for, with the better protection of the child population and the larger percentage of surviving infectious persons, the tendency will be for infection to occur later and to affect with increasing frequency the more susceptible adolescent age group.

Hilar Adenitis.-Because a close association exists between the glandular component of the primary complex and the pathogenesis of complications, special attention was paid to hilar adenitis.

Though the numbers are small from the followup results available, it is difficult to continue to regard simple hilar adenitis as the benign process customarily represented. Hilar adenitis has been the starting point of changes resulting in a significant morbidity in this series, since, out of the 35 cases developing pulmonary complications, 16 originated in this group. No age group was exempt from these sequelae, our cases ranging from 12 months to 18 years, while the time elapsing between onset and extension also varied between wide limits (one month to three years). Nor does it seem that these cases can safely be regarded as uninfectious, since four were found to have positive sputa out of a total of 16 . These findings suggest that observation only is inadequate, especially where the infection is known to be recent and the child in the under-5 age group. A period of bed rest is necessary for all such cases and chemotherapy should be given. This, while not necessarily influencing the course of the adenitis present, has to date prevented haematogenous spread of the disease.

As regards any indication as to prognosis that hilar adenitis may give in an individual case, neither the degree of the enlargement nor the extent of the endobronchial changes was helpful in forecasting the outcome. The development of obstructive emphysema was not necessarily associated with a failure of resolution subsequently. A factor of significance appeared to be the length of time the adenitis took to resolve. In the 10 patients who had parenchymal lesions which resolved completely, satisfying the criterion of bronchography as well as serial radiographs, glandular resolution also occurred in less than a $f$ year (average eight months). At the other end of $\mathrm{S}$ the scale, in those where the pulmonary disease failed to improve, the glands were either found to have been enlarged for a correspondingly longer period (minimum 12 months) or in half showed no signs of regression at all.

In agreement with other writers, glandular enlargement on the right side appeared more liable to complications, which developed in $52 \%$ with right-sided adenopathy as opposed to $36 \%$ with glands on the left. While it seemed possible that this might be related to the work of Engel (1947), suggesting a special function for the glands on the right as a second line of defence irrespective of the side initially infected, scrutiny of 12 patients who had a primary complex in which a pulmonary focus was visible at the time, or became so later, did not support this idea.

Established calcification could not always be dismissed, since in eight of our patients the coexistence of activity and calcification was noted: 3 one child with well-defined calcification in the left upper lobe, giving every appearance of healed disease radiologically, produced a positive sputum. It was found that, where calcification appeared in an affected gland within six months, the outlook $\frac{7}{0}$ was usually good; where the time was longer the chances of relapse appeared appreciably higher. $\widetilde{N}$ In this connexion the absence of calcification in $N$ the cases with erosion is of interest.

Parenchymatous Disease.-The importance of these lesions lies in the permanent damage that theyco are apt to inflict. Complete resolution was found $\Phi$ only in a minority $(21 \%)$, while in a further small $\stackrel{\mathcal{Q}}{?}$ percentage $(13 \%)$, though there was no evidence $\frac{0}{0}$ of residual damage on standard radiography, $\frac{O}{\Phi}$ bronchiectasis could still be demonstrated. The $\stackrel{\square}{\rightarrow}$ percentage with symptoms $(55 \%)$-marked in $\stackrel{\mathbb{Q}}{\varrho}$ $21 \%$, mild in $34 \%$ - corresponds fairly well with other descriptions (Thomas and others, 1954), and 
indicates that in nearly half the cases in this group the process was silent.

In agreement with Bentley it was observed that permanent damage with symptomatic bronchiectasis only occurred in segmental lesions of the lower lobes, and, to a lesser extent, in the middle lobe. The importance of age also stood out, the two most severely affected being under 2 years old.

The same preponderance of girls was noted in the simple hilar adenitis group and in the parenchymatous disease group, thus confirming the importance of the glandular factor in the pathogenesis of segmental disease.

Where chemotherapy was given in this series the most usual combination was that of streptomycin and isoniazid, and the minimum duration of treatment was 10 weeks. Although chemotherapy had little immediate effect upon the lesions its value is demonstrated by the complete absence of haematogenous spread and the higher rate of resolution amongst those to whom it was given.

Pleural Effusion.-In this group the glandular factor was not prominent in the causation of the condition, hilar adenitis being found in less than half the patients. Where glands were present it was noticeable that complications occurred more frequently, and in this series intrapulmonary lesions were found in association with right-sided effusions and pleural thickening when the glands were on the left. Though thickening was gross in three cases reliance on medical treatment was proved to be justified, complete resolution occurring in all three with a good functional end-result. The value of streptomycin was most evident where the effusion was unassociated with hilar adenitis and presumably the result of haematogenous spread.

MAJOR SURGERY.-The indications for surgery in primary tuberculosis are the relief of respiratory distress and the later control of symptomatic bronchiectasis. Glandular abscesses, not responding to treatment, with which there may be associated segmental disease, also appear to provide a rational indication for operative treatment, and our opinion of the value of such measures was reinforced by the finding of actively caseous disease in all but one of the resected specimens. Such a segment must be functionless if left and could be dangerous. But only protracted follow-up with control cases treated with chemotherapy alone can be decisive in establishing the value of this procedure. There may also be a place for surgery to anticipate extension and so avoid an illness which may be prolonged and the possible precursor of adult disease.

\section{SUMMARY}

A study of primary pulmonary tuberculosis has been made in western Cornwall over a three-year period, with special reference to the incidence of the disease and its complications and to see how its subsequent behaviour accorded with the conflicting views of the conservative and surgical schools of thought.

Ninety-nine patients were diagnosed or were ill during this period, representing, as judged by the incidence of primary disease in 13-year-old schoolchildren, an estimated morbidity of approximately $1 \%$.

The disease progressed in 35 patients, and the importance of hilar adenitis in the pathogenesis of complications is shown.

It was also recognized that progression was more likely:

(a) When the infection occurred in the very young.

(b) When the disease was on the right, lesions on this side being twice as prone to extend as those on the left.

(c) When glandular enlargement persisted for more than a year and calcification was delayed.

(d) When bed rest and chemotherapy had not been given.

The overall prognosis was good; in only one patient was there extrapulmonary spread; there were no deaths.

Extension of disease to the lung parenchyma was frequent and occurred in almost half the cases. The morbidity to date has been low, and only time will tell how those treated with chemotherapy will compare with those in which resection was performed.

Structural damage as evidenced by bronchographic abnormalities occurred in almost a third (31\%). The resulting loss of function is considered to be minimal in the majority.

Surgery was essential in a small minority (2\%). The value of resecting caseous lung lesions has yet to be proved. No means have been found of anticipating which patients benefit from prophylactic adenectomy.

It is a pleasure to record our thanks to Mr. H. V. Wingfield, who undertook the operative treatment and bronchoscopic investigations, to $\mathrm{Dr}$. J. K. Lewis for his help with bronchography, our medical colleagues for access to case records, and Dr. Hargreaves, the Deputy Medical Officer of Health, for statistical data. Our special thanks are due to Miss M. V. Carlyon for her untiring efforts in the collection of our material and the preparation of the manuscript. 
REFERENCES

Adler, D., and Richards, W. F. (1953). Thorax, 8, 223. Bentley, F. J., Grzybowski, S., and Benjamin, B. (1954). Tuberculosis in Childhood and Adolescence. NAPT, London.

Derham, R. J. (1956). Texas St.J. Med., $52,583$.

Emerson, P. A. (1957). Lancet, 2, 674.

Engel, S. (1947). The Child's Lung. Arnold, London.

Huish. D. W. (1956). Thorax, 11, 186.

Joint Tuberculosis Council (1955). The Changing Character of Tuberculosis.

Jones, E. M., Rafferty, T. N., and Willis, H. S. (1942). Amer. Rev. Tuberc., 46, 392.
Jones, E. M., Peck, W. M., and Willis, H.S. (1946). Amer.J. Dis. Child., $\overrightarrow{\overline{\vec{F}}}$ 72, 296.

Macpherson, A. M. (1954). Postgrad. med. J., 30, 288.

and Lutwyche, V. U. (1950). Thorax, 5, 1 .

Richards, W. F. (1944). Proc. roy. Soc. Med., 37, 589.

Roberts, J. C., and Blair, L. G. (1950). Lancet, 1, 386.

Seal, R.M. E. (1956). Personal communication.

- and Thomas, D. M. E. (1956). Lancet, 2, 995.

Thomas, D. (1952). Proc. roy. Soc. Med., 45, 743.

Thomas, J. H., Morgan, D. B., and Davies, T. W.(1954). Brit. me.l.J., 2, 1325 .

Wallgren, A. (1956). Acta paediat. (Uppsala), 45, 471.

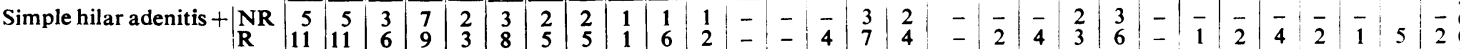

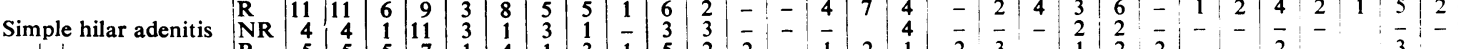

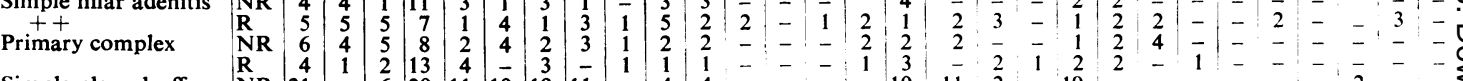

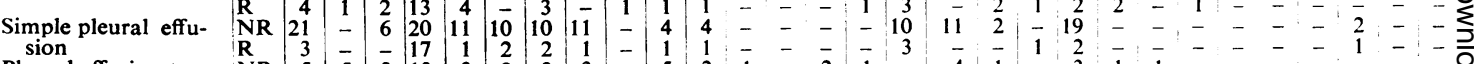

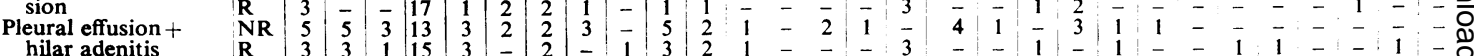

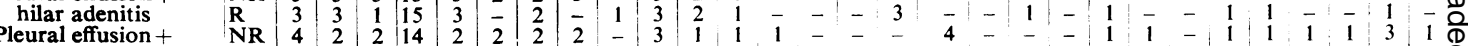

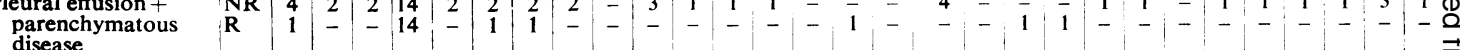

Parenchymatous

disease

\begin{tabular}{|l|l|l|l|l|l|l|l|l|l|l|l|l|l|l|l|l|l|l|l|l|l|l|l|l|l|l|l|l|l|l|l|l|} 
NR & 18 & 14 & 13 & 7 & 10 & 8 & 6 & 11 & 1 & 15 & 8 & 3 & - & 4 & 2 & 2 & 14 & 1 & 1 & 1 & 8 & 9 & - & 3 & 4 & 1 & -12 & $-\overline{0}$ \\
\hline
\end{tabular} Miliary

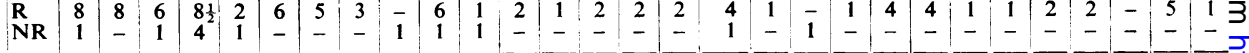

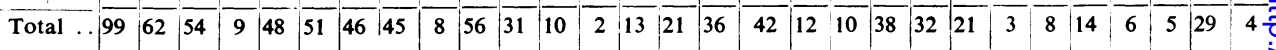

TABLE II

TUBERCULOUS COMPLICATIONS RELATIVE TO DISEASE ON PRESENTATION

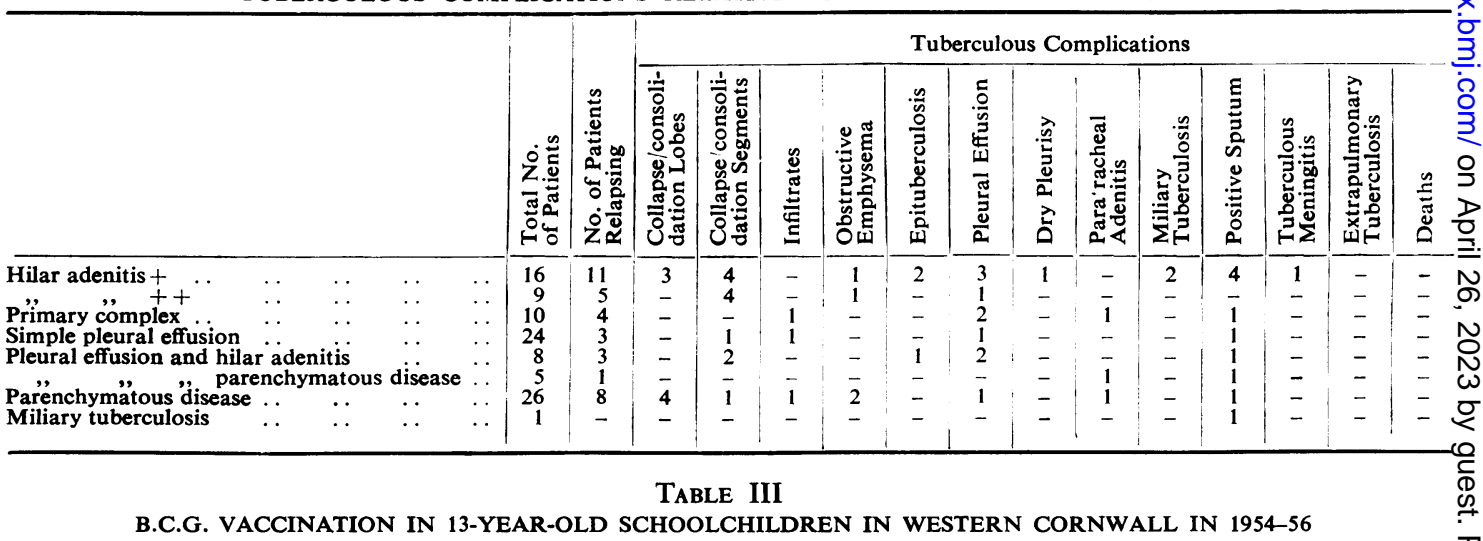

\begin{tabular}{|c|c|c|c|c|}
\hline \multirow{2}{*}{ Year } & \multicolumn{3}{|c|}{ Mantoux Testing (1: 100 I.U.) } & \multirow{2}{*}{$\begin{array}{c}\text { No. Children with Active } \\
\text { Primary Pulmonary } \\
\text { Tuberculosis }\end{array}$} \\
\hline & Total Tested & $\%$ Accepting & Total Mantoux Positive & \\
\hline $\begin{array}{l}1954 \\
1955 \\
1956\end{array}$ & $\begin{array}{l}1,853 \\
2,458 \\
2,360\end{array}$ & $\begin{array}{l}88 \\
92 \\
90\end{array}$ & $\begin{array}{l}425(23 \%) \\
462(20 \%) \\
453(19 \%)\end{array}$ & $\begin{array}{l}44 \\
8 \\
1\end{array}$ \\
\hline
\end{tabular}

